\title{
QUALIDADE DO LEITE DE VACAS COLETADO EM ORDENHA MECÂNICA E MANUAL EM PROPRIEDADES NA REGIÃO DE ARAMINA-SP
}

VIEIRA, Vânia Moyzés Cheibub ${ }^{1}$

CARDOSO JUNIOR, Guido ${ }^{2}$

DANEZE, Edmilson Rodrigo ${ }^{3}$

MELLO, Silvio de Paula ${ }^{4}$

RESUMO: Conduziu-se um ensaio na região de Aramina-SP, no período de janeiro a julho de 2006, com o objetivo de avaliar a qualidade do leite ordenhado mecânica e manualmente em duas propriedades da região de Aramina-SP. Para isso, foram realizados testes de acidez, densidade e crioscopia. Ao final do experimento podese concluir que o leite proveniente de ordenha mecânica apresentou resultados melhores com relação à ordenha manual, com médias de $16,40^{\circ} \mathrm{D}$ (Dornic) para acidez, densidade de 1030,02 g/litro e crioscopia de $-0,538^{\circ} \mathrm{C}$.

Palavras-chave: Qualidade. Leite. Bovinos.

\section{MILK QUALITY OF MECHANIC AND MANUAL MILK IN TWO FARMERS IN THE REGION OF ARAMINA-SP}

\begin{abstract}
SUMMARY: We conducted a test in the region of Aramina-SP, in the period of January to July 2006 with the aim of evaluating the quality of milk milked mechanically and manually in two farmers in the region of Aramina-SP. For this, acidity, density and freezing point tests were performed. At the end of the experiment we can conclude that milk milked showed better results compared with hand manual milked, with averages of 16.40 ${ }^{\circ} \mathrm{D}$ (Dornic) for acidity, density of $1030.02 \mathrm{~g} /$ liter and freezing point of $-0.538^{\circ} \mathrm{C}$.
\end{abstract}

Keywords: Quality. Milk. Cattle.

\section{INTRODUÇÃOO}

O leite, obtido em circunstâncias naturais, é uma emulsão de cor branca, ligeiramente amarelada, de odor suave e gosto adocicado. É um alimento completo, rico em proteínas, gorduras, carboidratos, vitaminas naturais, e pequena quantidade de outros produtos, entre eles: lecitina, ureia, aminoácidos, ácido cítrico, ácido acético, álcool, lactocromo e enzimas. É formado na glândula mamária dos mamíferos, sendo secretado livre de bactérias. Entretanto, pode ser contaminado após a ordenha por micro-organismos presentes no corpo do animal, nas mãos do ordenhador, em vasilhames usados para acondicionamento pós-ordenha ou,

\footnotetext{
${ }^{1}$ Engenheira de Alimentos. Especialista. Professora dos cursos de Agronomia e Medicina Veterinária da FAFRAM/FE

${ }^{2}$ Engenheiro Agrônomo.

${ }^{3}$ Graduando em Medicina Veterinária da FAFRAM/FE

${ }^{4}$ Zootecnista. Prof. Dr. Prof. FAFRAM/FFCL/ FE.
} 
ainda, pelo contato direto com o solo ou fezes, ou indiretamente através de aerossóis (BEHMER, 1995).

Holmes; Wilson (1989) citam que outra causa de contaminação do leite são infecções das glândulas mamárias, conhecidas como mastite, sendo a higiene fator determinante para produção de um leite de boa qualidade. As infecções podem ocorrer via corrente sanguínea ou por via ascendente, através do canal do teto.

O tipo de ordenha, seja manual ou mecânica, pode influenciar na qualidade do leite. Por isso, práticas higiênicas durante o processo são importantes para que o leite mantenha sua qualidade e não perca seu valor nutritivo. No conceito atual de globalização de mercados, descuidar da qualidade e da inocuidade dos produtos lácteos é arriscar a perda dos mercados internos e externos, limitando o crescimento e desenvolvimento do setor.

Os alimentos de origem animal estão entre as maiores preocupações dos consumidores. O resultado é um conceito mais amplo de Qualidade Total, que pode ser aplicado aos produtos lácteos: qualidade higiênica ou inocuidade, qualidade composicional, qualidade nutricional, qualidade sensorial e qualidade tecnológica, apropriada para processamento, transformação, armazenagem e distribuição (FAO, 2004). Todas as exigências dos consumidores, respeitando o bem estar dos animais e sem poluição ambiental, se traduzem em ações coordenadas e integradas de controle de qualidade dos alimentos e certificação dos mesmos, através de processos de produção, coleta, transporte, transformação, processamento, armazenamento e comercialização.

Para determinar a qualidade do leite que é entregue nos laticínios são feitos vários testes, tais como: densidade, crioscopia (teor de água) e acidez. Dentro deste contexto, o presente trabalho teve por objetivo avaliar a qualidade do leite entre dois rebanhos, sendo um proveniente de ordenha mecânica e outro de ordenha manual.

\section{MATERIAL E MÉTODOS}

Foram coletadas, semanalmente, amostras do leite de duas propriedades leiterias e, posteriormente, levadas para o laboratório, onde foram feitas as análises de acidez $\left({ }^{\circ} \mathrm{D}\right.$ Dornic), densidade e crioscopia (teor de água) das mesmas, sendo as análises realizadas no laboratório de um laticínio localizado numa fazenda de criação de bovinos leiteiros do município de Aramina-SP.

Na propriedade A, localizada no município de Aramina-SP, foi analisado o leite proveniente de um rebanho constituído por 14 animais da raça Girolanda, com média de produção de 19,28 kg de leite por animal. Os animais eram ordenhados duas vezes ao dia, 
com ordenha mecânica e sem bezerro ao pé. O leite era recolhido em latões e encaminhado diretamente a usina de beneficiamento. Nessa propriedade eram tomados alguns cuidados profiláticos como vacinação contra Febre Aftosa, Brucelose e Tuberculose, além de ser feito o teste da caneca de fundo preto para diagnóstico de mastite associados ao pré-diping e pósdiping preventivos. Os animais eram tratados a pasto de Brachiaria decumbens, além de ser fornecida silagem de milho, ração concentrada com $22 \%$ de proteína bruta e sal mineral à vontade.

A propriedade B, localizada no município de Buritizal-SP, possui um rebanho constituído por 35 animais da mesma raça, com média de produção de 4,28 kg de leite por animal. Os animais eram ordenhados uma vez ao dia, com ordenha manual e com bezerro ao pé. O leite era recolhido em latões e encaminhado diretamente a usina de beneficiamento. Nessa propriedade, como cuidado profilático, eram feitas apenas as vacinações contra Febre Aftosa, Brucelose e Tuberculose, não sendo feitos testes para diagnóstico nem prevenção de mastite. Os animais eram tratados a pasto, com piquetes de braquiaria (Brachiaria decumbens), capim-mombaça (Panicum maximum), tifton e grama estrela africana (Cynodon spp), além de ser fornecida ração concentrada composta de uréia, farelo de soja e milho triturado.

As amostras foram coletadas num período de 7 meses, compreendendo janeiro a julho de 2006, num total de quarenta amostras. No laboratório, foram feitos os testes de acidez $\left({ }^{\circ} \mathrm{D}\right)$, densidade (g/litro) e crioscopia $\left({ }^{\circ} \mathrm{C}\right)$. Nas determinações foram empregados reagentes com pureza analítica e nas concentrações exigidas para cada análise.

\section{RESULTADOS E DISCUSSÃO}

Verifica-se, de acordo com a Tabela 1, que as médias para acidez, densidade e crioscopia, obtidas em cada tipo de ordenha, apresentam valores estatisticamente diferentes.

TABELA 1- Valores referentes à acidez, densidade e crioscopia encontrados nos lotes de leite avaliados.

\begin{tabular}{lccc}
\hline Tipos de ordenha & \multicolumn{3}{c}{ Características } \\
\cline { 2 - 4 } & Acidez $\left({ }^{\circ} \mathrm{D}\right)$ & Densidade $(\mathrm{g} /$ litro $)$ & Crioscopia $\left({ }^{\circ} \mathrm{C}\right)$ \\
\hline Mecânica & $16,40 \mathrm{~b}$ & $1030,02^{\mathrm{a}}$ & $-0,538^{\mathrm{a}}$ \\
Manual & $17,07^{\mathrm{a}}$ & $1028,32 \mathrm{~b}$ & $-0,531 \mathrm{~b}$ \\
Média Final & 16,74 & 1029,17 & $-0,534$ \\
C.V. $(\%)$ & 3,74 & 4,55 & 0,78
\end{tabular}

Médias seguidas de letras distintas, na coluna, diferem estatisticamente pelo teste de Tukey a 5\% ( $\mathrm{P}<0,05)$. 
Para a característica acidez, as médias encontradas foram de $16,40^{\circ} \mathrm{D}$ para ordenha mecânica e $17,07^{\circ} \mathrm{D}$ para ordenha manual. Arcuri et al (2006) citam que, dependendo da composição, a acidez do leite varia de $0,13 \%$ a $0,17 \%$ de ácido lático $\left(13^{\circ} \mathrm{D}\right.$ a $\left.17^{\circ} \mathrm{D}\right)$. O sabor ácido começa a ser percebido quando a acidez se eleva acima de 0,20\% (20²) de ácido lático.

Voutsinas et al (1990), analisando cabras de raça Alpina, encontraram resultados parecidos para acidez, em torno de $16,76^{\circ} \mathrm{D}$. Cunha Neto (2003) encontrou valores entre $14^{\circ} \mathrm{D}$ E $20^{\circ} \mathrm{D}$ para acidez em leite de búfala, referindo ao alto teor de proteínas no mesmo, em especial a caseína. Em suas análises, com rebanho bubalino de diversas raças, Tonhati et al (1998) encontraram variação entre $15,7^{\circ} \mathrm{D}$ e $19,01^{\circ} \mathrm{D}$. Valores estes acima dos padrões regulamentados para o leite de vaca, que é de $18^{\circ} \mathrm{D}$. Porém, Benevides et al (2001), analisando a acidez titulavel no leite de búfalas da raça Murrah, encontraram médias diárias entre $14^{\circ} \mathrm{D}$ e $18^{\circ} \mathrm{D}$, sendo as mesmas inferiores aos citados anteriormente. Tais comparações revelam que os resultados verificados se assemelham com os resultados encontrados pelos autores do presente trabalho.

Quanto à densidade, as médias encontradas foram de 1030,0 g/litro e 1028,0 g/litro para ordenha mecânica e manual, respectivamente. A média mais baixa verificada na ordenha manual pode estar associada às condições de alimentação do rebanho, a idade e genética do rebanho, ou onde os teores de nutrientes exigidos pelo animal para produção de leite podem estar insuficientes para manterem uma boa consistência do mesmo. A densidade é um fator relacionado ao teor de matéria seca e de matéria graxa do leite.

Segundo Mens (1985), a densidade do leite de cabra esta situado entre 1026,0 a 1042,0 g/litro, dependendo de fatores como leite individual ou de mistura, e variando conforme as estações do ano, estado fisiológico e raça do animal. Enquanto, Voutsinas et al (1990), em estudo com cabras de raça alpina, obteve média de 1030,0 g/litro, variando entre 1027,0 e 1032,0 g/litro. Quanto ao leite de vaca, Parkash; Jeness (1968) discriminam valores médios de 1029,0 a 1036,0 g/litro. No Brasil, foram encontrados valores na ordem de 1033,1 g/litro (GIGANTE; ROIG, 1994) e 1031,05 g/litro \pm 0,20 (BONASSI et al, 1997) para densidade do leite bovino. Como linha geral, o leite de búfala apresenta densidade entre 1025,0 a 1047,0 g/litro segundo Kosikowski (1979), Furtado (1980) e Cunha Neto (2003).

Para a crioscopia, pode-se inferir que o maior resultado apresentado pela ordenha mecânica, em relação à ordenha manual, pode ser atribuído a melhor qualidade da alimentação oferecida aos animais, idade e a genética do rebanho, assim como a uma serie de 
fatores relacionados ao animal, ao leite, ao ambiente, ao processamento e as técnicas crioscópicas, ocasionando dificuldades para o estabelecimento de padrões (PEREIRA, 2000). O ponto crioscópico de leite de vaca aproxima-se de $-0,545^{\circ} \mathrm{C}$ (FAO, 2004), sendo mais baixo que o ponto crioscópico do leite de cabra, que se aproxima de $-0,583^{\circ} \mathrm{C}$ (MENS, 1985). Justificado por Parkash; Jeness (1968), que descrevem que o leite de cabra contém mais moles de soluto/1000 g de água que o leite de vaca.

No Brasil, Pombo; Furtado (1978) encontraram média de $-0,565^{\circ} \mathrm{C}$, na variação de $0,549^{\circ} \mathrm{C}$ e $-0,596^{\circ} \mathrm{C}$, Gigante; Roig (1994) em seu estudo encontraram média de $-0,576^{\circ} \mathrm{C}$, com variação entre $-0,546^{\circ} \mathrm{C}$ e $-0,596^{\circ} \mathrm{C}$, enquanto Bonassi, et al (1997) encontraram valores médios de $-0,560^{\circ} \mathrm{C}$, variando entre $-0,531^{\circ} \mathrm{C}$ e $-0,580^{\circ} \mathrm{C}$. De acordo com Kosikowski (1979), Furtado (1980) e Cunha Neto (2003) o leite de búfala apresenta crioscopia entre $-0,531^{\circ} \mathrm{C}$ e $-0,548^{\circ} \mathrm{C}$, sendo muito semelhante ao leite bovino, que $0,545^{\circ} \mathrm{C}$. FAO (2004) considera valores acima de $-0,530^{\circ} \mathrm{C}$ correspondem a leite adulterado, para ambas as espécies.

\section{CONCLUSÃO}

Na ordenha de leite de vacas, a ordenha mecânica apresentou melhores resultados para acidez, densidade e crioscopia que a manual. A média mais alta, verificada na ordenha manual, pode ser devido às condições de manejo do rebanho.

\section{REFERÊNCIAS}

ARCURI, E.F.; BRITO, J.R.F.; BRITO, M.A.V.P. Balde Branco. n.489. 27 jan 2006.

BEHMER, M.L.A. Tecnologia do leite: leite, queijo, manteiga, caseína, iogurte, sorvetes e instalações: produção, industrialização, análise. 15 ed. São Paulo: Nobel, 1995. p.15-16; 19.

BENEVIDES, C.M.J.; TRIGUEIRO, I.N.; SANTOS, M.A.F. Estudo da variação da produção e do teor de gordura do leite de búfala (Raça Murrah) na microrregião de Catu-BA em 165 dias de lactação. Higiene alimentar, v.15, n.80/81, p.100, 2001.

BONASSI, I.A.; MARTINS, D.; ROÇA, R.O. Composição química e propriedades físicoquímicas do leite de cabra. Ciênc. Tecnol. Aliment., Campinas, v.17, n.1, p.57-63, 1997.

CUNHA NETO, O.C. Avaliação do iogurte natural produzido com leite de búfala contendo diferentes níveis de gordura. 2003. 71f. Dissertação (Mestrado em Zootecnia) Faculdade de Zootecnia e Engenharia de alimentos da Universidade de São Paulo, Pirassununga. 
FAO: Seguridad alimentaria como estratégia de desarollo rural. In: MONARDES, H.

Reflexões sobre a qualidade do leite. In: DÜRR, J.W.; CARVALHO, M.P. de; SANTOS, M.V. dos (org.). O compromisso com a qualidade do leite no Brasil. Passo Fundo: UPF, 2004. p.17.

FURTADO, M. M. Composição centesimal do leite de búfala na zona da mata mineira. Rev. Inst. Latic. Cândido Tostes, v.35, n.211, p.43-47, 1980.

GIGANTE, M.L.; ROIG, S.M. Características físico-químicas do leite de cabra da região de São José do Rio Preto-SP. In: CONGRESSO BRASILEIRO DE CIÊNCIA E TECNOLOGIA DE ALIMENTOS, 14, São Paulo, 1994. Anais... São Paulo, 1994, 40p.

HOLMES, C.W.; WILSON, G.F. Produção de leite à pasto. Campinas: Instituto Campineiro de Ensino Agrícola, 1989. P.472-475.

KOSIKOWSKI, F. V. Cheese and fermented milk foods. 3.ed. Ann Arbor, MI: Westport Brothers, 1979. 2v.

MENS, P. Le. Propriétés physico-chimiques nutritionelles et chimiques. In: Lait et produits laitiers. Paris, tec. Doc. Lavoisier, 1985, v.1, parte 3, cap.1, p.349-368.

PARKASH, S.; JENESS, R. The composition and characteristics of goats milk: a review. Dairy Sci. Abs., v.40, n.2, p.67-87, 1968.

PEREIRA, D.B.C. Físico-química do leite e derivados: métodos analíticos. 2.ed. Juiz de Fora: Oficina, 2000. 190p.

POMBO, W. A. F.; FURTADO, M. M. Fabricação do queijo tipo Chabichou. In: Algumas características físico-químicas do leite de cabra na zona da mata mineira. Rev. Inst. Latic. Cândido Tostes, v.33, n.200, p.3-11, 1978.

TONHATI, H. et al. Controle leiteiro em búfalas. In: SIMPÓSIO NACIONAL DE MELHORAMENTO ANIMAL, 2. Uberaba, Anais..., SBMA, p.53-58, 1998.

VOUTSINAS, L.; PAPPAS, C.; KATSIARI, M. The composition of Alpine goat's Milk during lactation in Greece. J. Dairy Sci., n.57, p.41-51, 1990. 